\section{STANDARD MANUAL BRUSHES}

Sir, in response to the letter by $\mathrm{L}$. Mackenzie (BDJ 2014; 217: 612-613), Toothbrushing evolution, I would like to address the points he raised about our paper (BDJ 2014; 217: E5). We acknowledge the conclusions of the 1998 European Workshop on Mechanical Plaque Control Review1 reiterating the statement in the 1986 World Workshop ${ }^{2}$ that 'improvement in oral hygiene is not as dependent upon the development of better brushing methods as upon improved performance by the persons using any one of the accepted methods'. Indeed, Levine and Stillman-Lowe in the BDJ book The scientific basis of oral health education ${ }^{3}$ agree with us that 'The precise technique is less important than the result' and that 'a gentle scrub technique is effective for most people and is easy to teach and readily accepted'. Our study indicated, however, that this statement did not appear to have influenced advice on toothbrushing method provided by professional sources.

The Beals et al. paper ${ }^{4}$ quoted by Mackenzie is about efficacy of a toothbrush with a special design, whilst the systematic reviews ${ }^{5-7}$ quoted concern powered brushing. Whilst we know that different toothbrush designs - including powered brushes - may have an effect on plaque control, the focus of our study was on standard manual brushes which the vast majority of the global population use. Powered toothbrushes or those of special design may cost several times what a manual brush may cost, and are thus not affordable by a large section of society.

It is prudent to note our paper aimed not to determine a best toothbrushing method, but to assess the variation in the method recommended. The literature review was selective in addressing stated aims we hoped to achieve.

\section{J. Wainwright, by email}

1. Jepsen $\mathrm{S}$. The role of manual toothbrushes in effective plaque control, advantages and limitations. In Lang N P, Attström R, Löe H (eds). Proceedings of the European Workshop on Mechanical Plaque Control. pp 121-137. Chicago: Quintessence Publishing Co., 1998.

2. Frandsen A. Mechanical oral hygiene practices. In Löe H, Keinman D V (eds). Dental plaque control measures and oral hygiene practices. pp 93-116. Oxford, Washington DC: IRL Press, 1986.

3. Levine R, Stillman-Lowe $C$. The scientific basis of oral health education, 6th ed. London: BDJ Books, 2009.

4. Beals D, Ngo T, Feng $\vee$ et al. Development and laboratory evaluation of a new toothbrush with a novel brush head design. Am J Dent 2000; 13 Special Issue: $5 A-14 A$

5. Heanue M, Deacon S A, Deery C et al. Manual versus powered toothbrushing for oral health. Cochrane Database Syst Rev 2003; CD002281.

6. Robinson P, Deacon S A, Deery C et al. Manual versus powered toothbrushing for oral health. Cochrane Database Syst Rev 2005: CD002281.

7. Yaacob M, Worthington H V, Deacon S A et al. Powered versus manual toothbrushing for oral health. Cochrane Database Syst Rev 2014; CD002281.

DOI: 10.1038/sj.bdj.2015.158 to bilateral subjects and bilateral IANBs have been problem free even in children. ${ }^{3}$ Extracting both impacted third molars at the same appointment reduces chairside time for patient and clinician, the anxiety associated with a second procedure and lowers healthcare costs as time and materials are considerably less for one-stage procedures. However, there is an absence of guidelines on the use of bilateral IANBs. ${ }^{1}$

Informing the patient prior to third molar surgery about the possible chances of the tongue falling back resulting in respiratory embarrassment should be the first step although the surgeon and his/ her assistant must monitor this and make quick changes in chair position to avoid problems. Another guideline would be to pass a suture along the tip of the tongue as the entire dorsum of the tongue would be invariably anaesthetised, as this would give the surgical team an additional measure to quickly pull back the tongue in such an instance. Cases of lingual frenectomy are often performed with a suture passed around the tip of the tongue to gain clear access to the lingual frenum. These simple procedures by the clinicians would make bilateral IANBs safer with its various advantages but more work on this topic would help in framing proper guidelines.

Haydar M. Mahdey, Srinivas Ramachnadra, Preena Sidhu, by email

1. Jabbar J, Shekar V, Mitchell D A, Brennan P A. Should we be giving bilateral inferior alveolar and lingual nerve blocks for third molar surgery? Br J Oral Maxillofac Surg 2014; 52: 16-17.

2. Singh B. Mandibular nerve block for the removal of dentures during trismus caused by tetanus. Anesth Analg 2006; 103: 252-253.

3. College C, Feigal R, Wandera A, Strange M. Bilateral versus unilateral mandibular block anesthesia in a pediatric population. Pediatr Dent 2000; 22: 453-457.

DOI: 10.1038/sj.bdj.2015.157 